\title{
Microwave Mediated Fast Synthesis of Silver Nanoparticles and Investigation of Their Antibacterial Activities for Gram-Positive and Gram-Negative Microorganisms
}

Faheem Ahmed ${ }^{1, *}{ }^{10}$, Suliman Yousef AlOmar ${ }^{2}\left(\mathbb{D}\right.$, Fadwa Albalawi $^{3}$, Nishat Arshi ${ }^{4}$, Sourabh Dwivedi ${ }^{5}(\mathbb{D}$, Shalendra Kumar ${ }^{1,6}{ }^{(}$, Nagih Mohammed Shaalan ${ }^{1} \mathbb{D}$ and Naushad Ahmad ${ }^{7}$

1 Department of Physics, College of Science, King Faisal University, P.O. Box-400, Al-Ahsa 31982, Saudi Arabia; sjagdish@kfu.edu.sa (S.K.); nmohammed@kfu.edu.sa (N.M.S.)

2 Doping Research Chair, Zoology Department, College of Science, King Saud University, Riyadh 11451, Saudi Arabia; syalomar@ksu.edu.sa

3 Department of Zoology, King Saud University, Riyadh 11451, Saudi Arabia; fadwa_saad@hotmail.com

4 Department of Basic Sciences, Preparatory Year Deanship, King Faisal University, P.O. Box-400, Al-Ahsa 31982, Saudi Arabia; nshastri@kfu.edu.sa

5 Department of Applied Physics, Aligarh Muslim University, Aligarh 202002, India; sourabh25june@gmail.com

check for updates

Citation: Ahmed, F.; AlOmar, S.Y.; Albalawi, F.; Arshi, N.; Dwivedi, S.; Kumar, S.; Shaalan, N.M.; Ahmad, N. Microwave Mediated Fast Synthesis of Silver Nanoparticles and Investigation of Their Antibacterial Activities for Gram-Positive and Gram-Negative Microorganisms. Crystals 2021, 11, 666. https:// doi.org/10.3390/cryst11060666

Academic Editors: Marilena Carbone, Assem Barakat and Alexander S. Novikov

Received: 28 April 2021

Accepted: 30 May 2021

Published: 10 June 2021

Publisher's Note: MDPI stays neutral with regard to jurisdictional claims in published maps and institutional affiliations.

Copyright: (c) 2021 by the authors. Licensee MDPI, Basel, Switzerland. This article is an open access article distributed under the terms and conditions of the Creative Commons Attribution (CC BY) license (https:// creativecommons.org/licenses/by/ $4.0 /)$.
6 Department of Physics, School of Engineering, University of Petroleum \& Energy Studies, Dehradun 248007, India

7 Department of Chemistry, College of Science, King Saud University, Riyadh 11451, Saudi Arabia; anaushad@ksu.edu.sa

* Correspondence: fahmed@kfu.edu.sa; Tel./Fax: +966-013589-6900

\begin{abstract}
Herein, a simple one-step microwave irradiation technique has been used to synthesize the silver nanoparticles using silver nitrate $\left(\mathrm{AgNO}_{3}\right)$ solution and cetyltrimethyl ammonium bromide $(\mathrm{CTAB})$ as a stabilizing agent. The crystals of as-prepared nanoparticles were studied using X-ray diffraction (XRD) and a selected area electron diffraction (SAED) pattern, confirming the single-phase face-centered cubic structure. The optical property measured using UV-Vis spectroscopy shows an absorption maximum at $420 \mathrm{~nm}$, which also confirms the formation of silver nanoparticles. Transmission electron microscopy (TEM) analysis revealed that the silver nanoparticles have a spherical shape with an average diameter of $\sim 6 \mathrm{~nm}$. The antibacterial properties of silver nanoparticles were investigated using both Gram-positive and Gram-negative microorganisms, such as Staphylococcus aureus, Pseudomonas aeruginosa, and Escherichia coli. Klebsiella pneumoniae, and Candida albicans. Results showed a highest zone of inhibition of about $35 \mathrm{~mm}$ against $P$. aeruginosa as compared with E. coli $(21 \mathrm{~mm})$, S. aureus $(30 \mathrm{~mm})$, K. pneumonia $(28 \mathrm{~mm})$, and C. albicans $(29 \mathrm{~mm})$. These studies suggested that silver nanoparticles prepared by this fast and effective method might be developed as antibacterial agents against an extensive range of microorganisms to control and stop the spreading and persistence of bacterial infections.
\end{abstract}

Keywords: silver nanoparticle; XRD; TEM; antibacterial; UV-Vis spectroscopy

\section{Introduction}

In the last few years, various attempts have been made to advance safe, more effective treatment protocols to overcome the challenges of antibiotic resistance. It is observed that the microorganisms are responsible for creating microbial pollution and contamination, which results in many problems in manufacturing and other vital fields, such as degradation and infection. Therefore, to overcome such problems, various research groups have studied new pasteurization and antibacterial techniques and tried to develop new, effective antibacterial reagents [1-3]. However, advancements in the field of nanotechnology attracted the attention of researchers in the growth of the pharmaceutical field. Since 
nanomaterials have a large surface area and high reactivity compared with bulk solids, as a result, nanoparticles display extraordinary physical, chemical, and biological properties.

A large amount of research has been reported on antibacterial activity using various nanoparticles like silica/iron oxide, silica, ferrites, $\mathrm{ZnO}, \mathrm{CuO}$, and metal nanoparticles [4-8]. Among diverse metal nanoparticles, silver nanoparticles are very encouraging because of their various unique properties, such as catalysis, electrochemical, and antimicrobial. It is also observed that silver nanoparticles exhibit high antimicrobial activity against various viruses and bacterias, such as Gram-positive and negative bacteria, fungi, protozoa, and certain viruses. Recently, it has been reported that silver nanoparticles have shown antitumor activity in many cancerous cell lines [9]. These excellent properties and several biomedical applications of silver nanoparticles make their use effective in different applications, such as antibacterial agents in apparel, diagnostic applicative biological tags, and biosensors, cosmetics, footwear, wound dressings, paints, and so forth [10]. However, it has been observed that silver nanoparticles display superior properties as compared with bulk material. These silver nanoparticles easily interact with other particles and improve antibacterial activity. According to the Mie summation, where particles' diameter is $<20 \mathrm{~nm}$, absorption in a UV range only depends on the dipole term [11]. Moreover, there are many reports which explain the antibacterial action of silver nanoparticles. Gu et al. [12] reported that vancomycin-covered silver and gold nanoparticles show better antibacterial activity as compared to antibiotics. Nida et al. showed the synthesis of stable silver-substituted hydroxyapatite nanoparticles with controlled morphology and particle sizes which was achieved by using CTAB as a surfactant. Their results revealed that these nanoparticles demonstrated anti-bacterial activity against Staphylococcus aureus, Bacillus subtilis, Pseudomonas aeruginosa, and Escherichia coli [13]. Hence, these results suggest that the synthesis of stable silver nanoparticles is a subject of great interest.

There are various methods that are used for the synthesis of silver nanoparticles, such as chemical reduction [14], electrochemical methods [15], radiation [16], laser ablation [17], photochemical methods [18], sonochemical methods [19], and sputtering [20]. Among these methods, the most popular one is the chemical reduction of silver salt in the presence of any stabilizing agent. Utilization of nontoxic chemicals and renewable materials has attracted significant attention due to their benefit in reducing environmental risk. However, the major challenge is to prepare nanoparticles of high purity and low polydispersity. Recently, microwave irradiation has been considered to be an effective and distinct heating method for the preparation of silver nanoparticles, and due to its exceptional features, such as short reaction time, quick volumetric heating, energy saving, and high reaction rate, it has attracted researchers' interest $[13,21]$.

Herein, we have reported on the easy, rapid, and cost-effective synthesis of spherical and monodispersed silver nanoparticles by the microwave irradiation method within 3 min of irradiation time which has shown excellent antibacterial efficiency against both grampositive and gram-negative bacteria. In particular, silver nanoparticles showed higher antibacterial activity for $P$. aeruginosa than that of E. coli, S. aureus, K. pneumoniae, and C. albicans.

\section{Experimental Details}

E. coli, S. aureus, K. pneumoniae, P. aeruginosa, and C. albicans were acquired from the 'JNMC', Aligarh Muslim University, India. All the chemicals used in this study were AR-grade materials and used without further purification. Silver nitrate $\left(\mathrm{AgNO}_{3}, 99 \%\right)$, oxalicacid (99.8\%), and cetyltrimethyl ammonium bromide (CTAB, 99.5\%) were procured from Sigma Aldrich, Missouri, United States. De-ionized water was used for aqueous solutions. For synthesis of silver nanoparticles, $10 \mathrm{~mL}$ of $5 \mathrm{mM} \mathrm{AgNO}_{3}, 0.2 \mathrm{gm}$ of oxalic acid, and $0.2 \mathrm{gm}$ of CTAB were mixed to get an aqueous solution. Further, the solution was stirred for $1 \mathrm{~min}$ and then kept in a microwave oven (SAMSUNG, Seoul, South Korea; $800 \mathrm{~W}$ ) for heating at $100 \%$ power of $800 \mathrm{~W}$ for $3 \mathrm{~min}$. Upon microwave irradiation, the colorless solution immediately turned into a characteristic pale-yellow color, repre- 
senting successful synthesis of silver nanoparticles. The benefit of microwave-mediated synthesis over conventional heating is the enriched kinetics of the reaction mostly by one or two orders of magnitude, due to fast initial heating and the generation of localized high-temperature zones at reaction sites [22]. The as-obtained product was used for the characterization.

The XRD pattern of as-synthesized silver nanoparticles was acquired using an $X^{\prime}$ pert MPD 3040 X-ray powder diffractometer using CuK $\alpha$ radiation $(\lambda=1.5418 \AA)$. Optical properties were measured by a UV-Vis Spectrophotometer (Agilent 8453, Santa Clara, CA, USA) with a $1 \mathrm{~cm}$ quartz cell.

Field emission transmission electron microscopy (FETEM; JEOL, JEM-2100F, Tokyo, Japan) was used to study the surface morphology and selected area electron diffraction (SAED) of the synthesized silver nanoparticles. In order to measure the TEM measurements, a small drop of nanoparticle solution was cast onto a carbon-coated copper grid and then dried in air before moving it to the microscope. Image J' software was used to determine the average particle size and the size distribution.

A variety of microorganisms, including Staphylococcus aureus (ATCC 25923), Escherichia coli (ATCC 25922), K. pneumonia (ATCC 700603), P. aeruginosa (ATCC 27853), and C. albicans (ATCC 10213) were used to study the antibacterial activity of silver nanoparticles. The standard agar-well diffusion method using standard strains of E. coli, S. aureus, and $P$. aeruginosa was used for silver nanoparticles' antibacterial activity. The bacterial strain used here was grown in Luria Bertani (LB) Broth at $37^{\circ} \mathrm{C}$ overnight up to a turbidity of $0.5 \mathrm{Mac}$ Farland standard $\left(10^{8} \mathrm{CFU}\right.$ perml) [23]. About $50 \mu \mathrm{L}$ of silver nanoparticle suspension was used to inoculate the petridish filled with LB agar. Wells were punched in the agar plates and filled with the nanoparticle solutions, and the LB agar plates were incubated overnight at $37^{\circ} \mathrm{C}$. The bacteria-free water extract alone and deionized Milli-Q water were used as controls. Samples treated with nanoparticles were spread on nutrient agar plates and after incubation at $37^{\circ} \mathrm{C}$ for $24 \mathrm{~h}$, the zones of inhibition were observed only in the presence of silver nanoparticles and documented.

\section{Results and Discussion}

The color transformation of the solution during synthesis clearly shows the formation of silver nanoparticles. The colorless silver nitrate solution changes to yellow at $3 \mathrm{~min}$ microwave irradiation. Figure 1 highlights the UV-Vis absorption spectrum of CTAB stabilized silver nanoparticles. It can be clearly seen from the spectrum that the absorption maxima occurred at $420 \mathrm{~nm}$. The absorption peak observed at $420 \mathrm{~nm}$ infers materialization of the silver nanoparticles, which is accredited to the Mie-scattering by silver metal [24].

The typical XRD pattern of the as-prepared silver nanoparticles is shown in Figure 2. The XRD pattern of silver nanoparticles revealed a single-phase nature with a face-centered cubic (FCC) structure. No secondary phase was detected within the detection limit of the XRD, and the high intensity of peaks confirmed the high crystalline nature of as-prepared silver nanoparticles. The XRD spectrum of silver nanoparticles point out characteristic peaks of silver which are allocated to the (111), (200), (220), and (311) planes of the facecentered cubic structure (FCC) (JCPDS 01-1167) [25,26].

The transmission electron microscopic measurement was conducted to study the size and morphology of the synthesized silver nanoparticles. The TEM micrograph of the synthesized silver nanoparticles is shown in Figure 3, which reflects that the nanoparticles are uniformly distributed and spherical in shape with an average diameter of $\sim 6 \mathrm{~nm}$. The diameter of the particles was measured using Image J software. The particles' size distribution histogram is plotted by using $\sim 100$ randomly selected nanoparticles from the TEM micrograph. The lower inset of Figure 3 shows the particle-size distribution plot of the synthesized silver nanoparticles. From the TEM micrograph, it can be seen that microwave synthesis gives highly monodisperse silver nanoparticles, with particle sizes ranging from 4.5 to $8.5 \mathrm{~nm}$ and an average size of $6.1 \mathrm{~nm}$. The crystalline nature of the silver nanoparticles was further revealed by the selected area electron diffraction (SAED) 
pattern. The typical SAED pattern of silver nanoparticles is shown in the upper inset of Figure 3 . The diffraction rings are clearly visible, and these can be indexed to the reflections of face-centered cubic (FCC) silver nanoparticles [27,28].

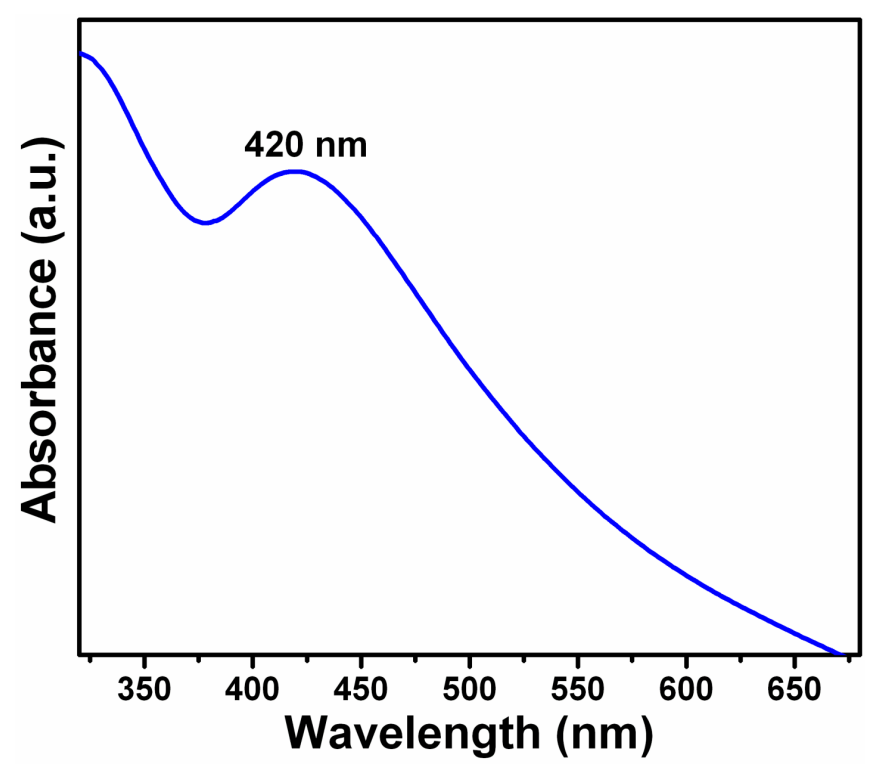

Figure 1. UV-Vis absorption spectrum of silver nanoparticles.

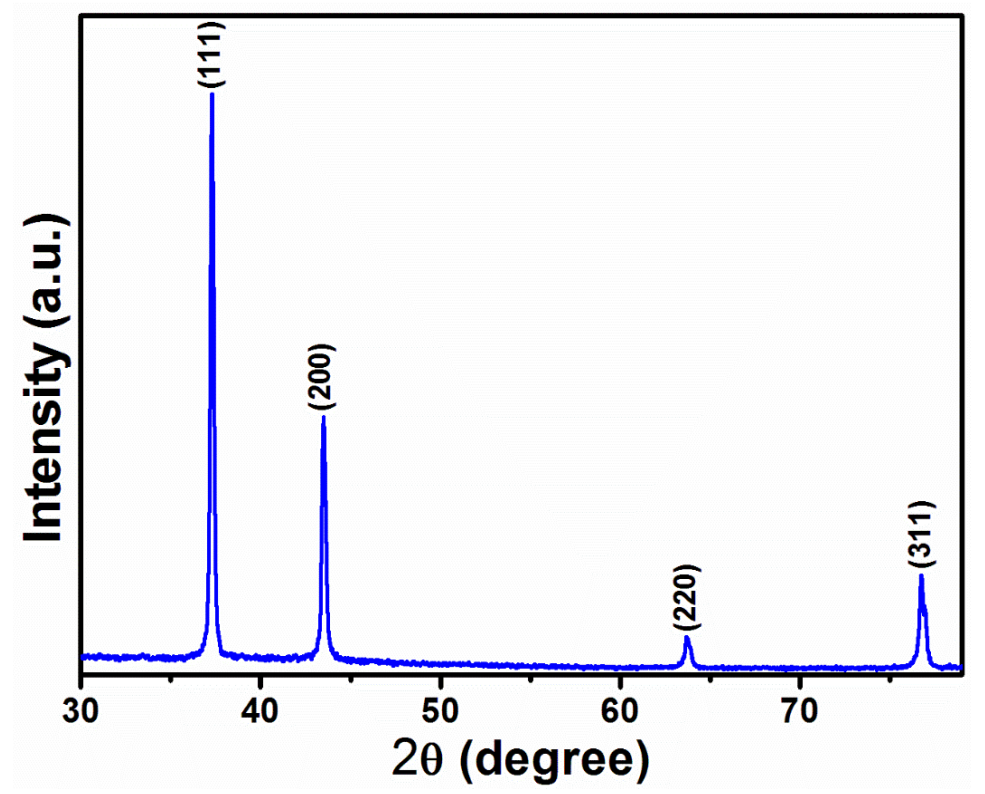

Figure 2. XRD pattern of silver nanoparticles.

The reduction of $\mathrm{Ag}^{+}$to $\mathrm{Ag}^{0}$ within 3 min of irradiation shows the successful formation of nanoparticles using the microwave irradiation method. The microwave irradiation utilizes the internal heat generated within the matrix and gives a complete reduction within a short duration of time. All these results give a clear suggestion of the highly crystalline nature of the silver nanoparticles synthesized by this method.

It is observed that as-synthesized silver nanoparticles revealed the broad spectrum of antimicrobial activities against Gram-negative and Gram-positive bacteria. The silver nanoparticles' exposure to three different test microorganisms, such as E. coli, S. aureus, and $P$. aeruginosa resulted in the formation of the zones of inhibition. The zones of inhibition studied in the silver nanoparticle solutions were 21, 30, 28, 35, and $29 \mathrm{~mm}$ for E. coli, S. aureus, K. pneumoniae, P. aeruginosa, and C. albicans, respectively, as shown in Figure 4. 
It is evident from Figure 4 that the largest zone of inhibition was observed for silver nanoparticles toward P. aeruginosa, while keeping the concentration of nanoparticles fixed. The efficient antimicrobial property of silver nanoparticles is because of their extremely large surface area, which delivers better contact with the microorganisms.

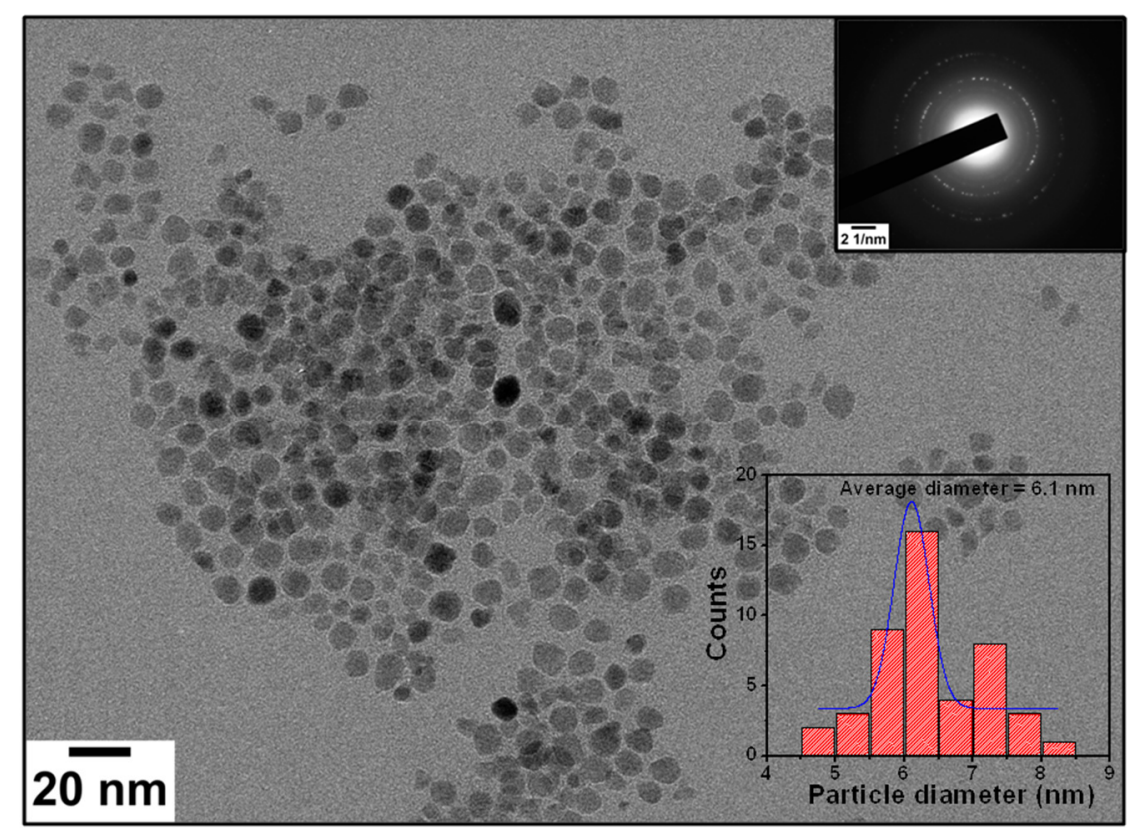

Figure 3. TEM image of silver nanoparticles. The upper inset shows the corresponding SAED pattern, and the lower inset shows the particle size distribution plot.
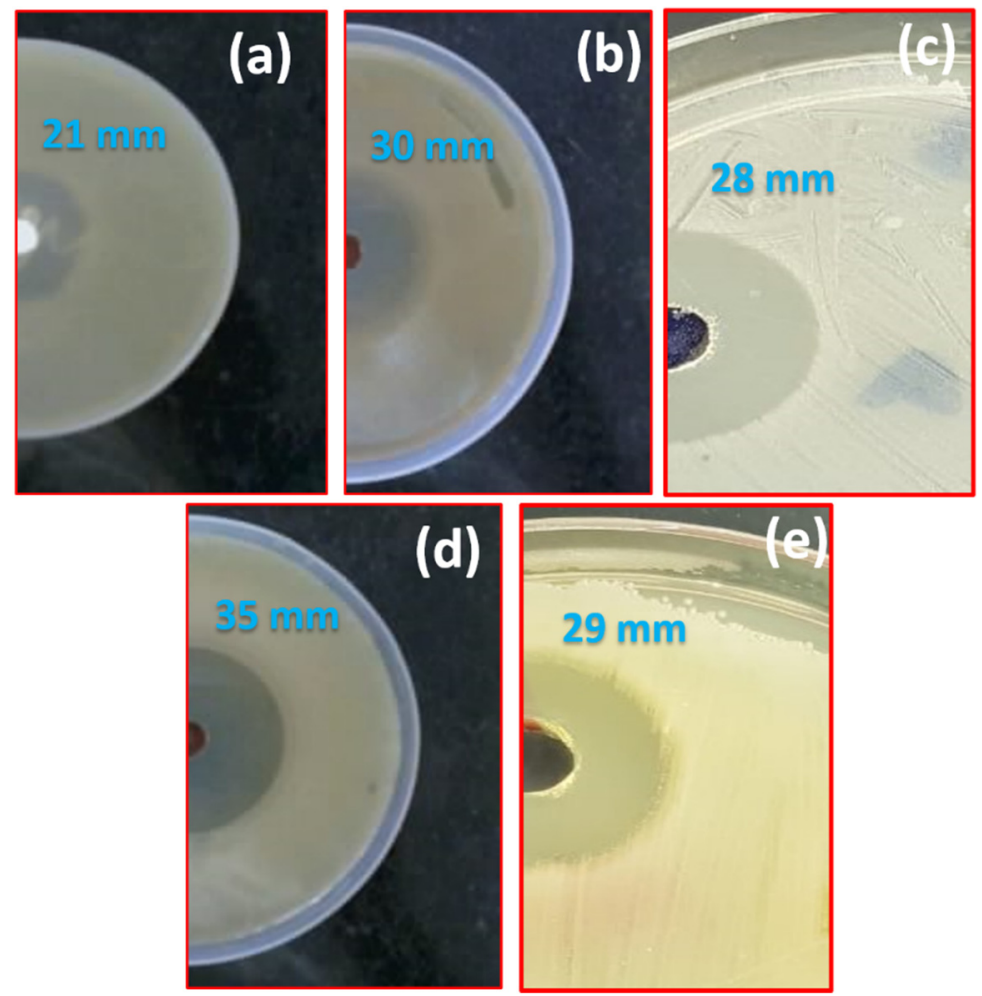

Figure 4. Zone of inhibition obtained with silver nanoparticles for (a) E. coli, (b) S. aureus, and (c) K. pneumoniae, (d) P. aeruginosa, and (e) C. albicans. 
The optical density (OD), which is used to measure the turbidity, is measured using a spectrophotometer. The bacterial inoculum is introduced into a liquid suspension of bacteria in a nutrient broth. It is observed that when the bacterial population in the suspension develops, the turbidity (optical density) of the suspension shall increase. The higher value of turbidity infers that the bacterial population is greater. It is found that the turbidity (optical density) of the solution reduces after introduction of an antimicrobial agent. This may happen due to the killing of the bacteria by an antimicrobial agent. This method delivers a fast and convenient approach of testing the anti-microbial properties of liquid formulations. Figure 5 displays growth curves of the E. coli, S. aureus, K. pneumoniae, P. aeruginosa and C. albicans strains in LB medium inoculated with $10^{8}$ CFU of bacteria in the presence of silver nanoparticles. The highest concentration of the silver nanoparticles $(50 \mu \mathrm{L})$ was found to strongly inhibit the growth of all the bacterial test strains.
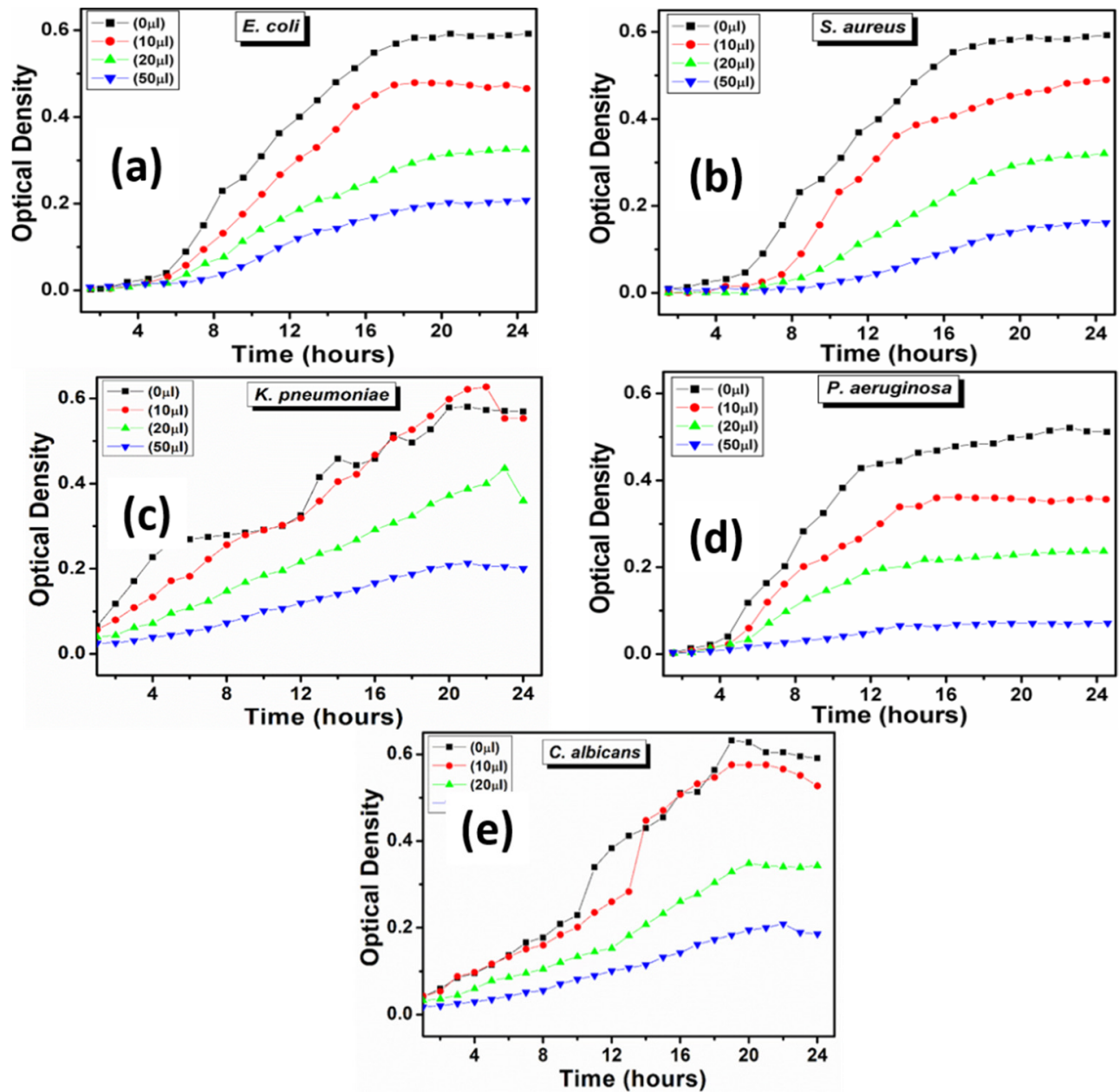

Figure 5. Growth curves of (a) E. coli, (b) S. aureus, and (c) K. pneumoniae, (d) P. aeruginosa, (e) C. albicans in the presence of silver nanoparticles.

We found that silver nanoparticles cause a growth delay in all the bacterial strains under all concentration used in the experiment. Figure 5 reflects the clear difference between antibacterial activities of the five microorganisms using silver nanoparticles (Figure 5a-d). We observed the silver nanoparticles exhibit the highest activity against $P$. aeruginosa, whereas it showed moderate activity against E. coli, S. aureus, K. pneumoniae and C. albicans. The small size of silver nanoparticles infers that it has a large surface area to come in contact with the bacterial cells, and as a result, it will have higher percentage of interaction [29]. Silver nanoparticles that are smaller than $10 \mathrm{~nm}$ interact with bacteria and generate electronic effects, which boost the reactivity of nanoparticles. 
The comparative analysis on the antibacterial activity of silver nanoparticles against E. coli, S. aureus, K. pneumoniae, P. aeruginosa and C. albicans is shown in Figure 6. This result indicates that antibacterial activity toward P. aeruginosa is higher than that toward E. coli, S. aureus, K. pneumoniae and C. albicans. It is well-known that the structure and chemical composition of the cell wall are quite different among E. coli, S. aureus, K. pneumoniae, $P$. aeruginosa, and C. albicans. In chemical stress, such as the environment including antibiotics, the tolerance in P. aeruginosa is usually weaker than that in E. coli. This might be a possible reason why antibacterial activity toward P. aeruginosa is stronger than toward that of E. coli, S. aureus, K. pneumoniae, and C. albicans [30].

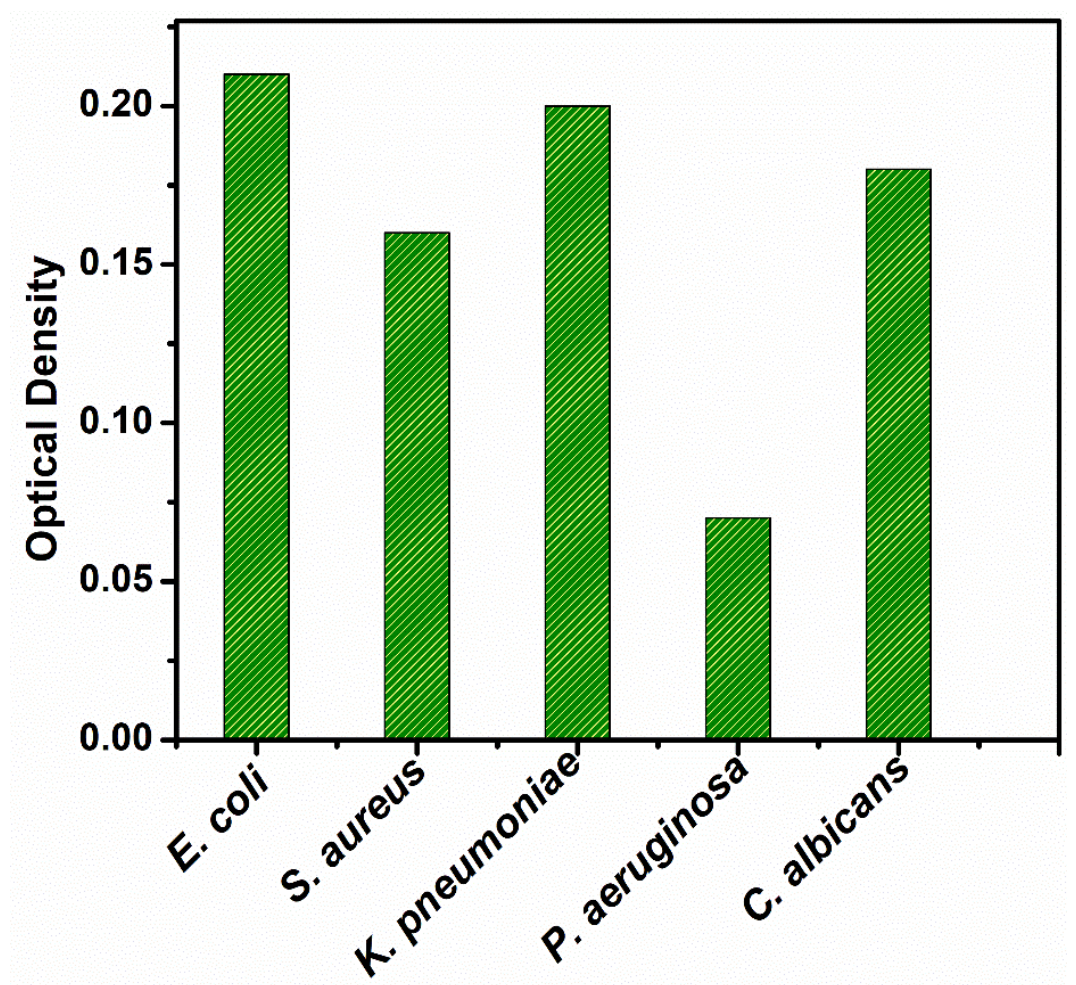

Figure 6. A comparative analysis on antibacterial activity of silver nanoparticles against E. coli, S. aureus, K. pneumoniae, P. aeruginosa, and C. albicans.

Antibacterial properties of silver nanoparticles against various pathogens have been reported by various researchers. Jun et al. [31] evaluated the effects of Ag nanoparticles on microorganisms against yeast, Escherichia coli, and Staphylococcus aureus. They observed that the low concentration of Ag nanoparticles was required for the inhibition of yeast and E. coli; however, S. aureus was found to show mild inhibition. In another work, Sheeana et al. [32] developed silver nanoparticle cluster coatings on the surfaces of copper. Their study was focused on the durability of the microbiocidal activity against pathogenic bacterial and fungal species, including Escherichia coli O157:H7 and Candida auris. The results showed that more than $90 \%$ of E. coli and C. auris were found to be non-viable. Other researchers [33] have prepared lichen-based Ag nanoparticles by using a green solid-state mechanochemical approach and evaluated the biological activity. In particular, they have compared the processing of lichen material of Pseudevernia furfuracea and Lobaria pulmonaria for extraction, as well as for synthesis of AgNPs, and tested the antibacterial and antioxidant activity of the extracts. Their results showed that due to the formation of AgNPs, the antibacterial activity was found to increase, while the antioxidant activity decreased. The influence of silver NPs as nano-food additives towards the human gut microbiome was investigated by Sheeana et al. [34].

Since most of the infection-causing multi-resistant bacterial strains have become a major warning to public health concerns, the high antibacterial activity of the silver 
nanoparticles concerning both gram-positive and gram-negative bacteria means that their use as antibacterial agents is recommended in preventing the outbreaks caused by the above pathogenic strains.

\section{Conclusions}

In summary, spherical and monodispersed silver nanoparticles have been successfully prepared under microwave irradiation by using oxalic acid as a reducing agent and CTAB as a binding agent. XRD results show the highly crystalline and face-centered cubic structure of the silver nanoparticles. TEM and the selected area electron diffraction pattern confirmed the formation of spherical and highly dispersed silver nanoparticles $(\sim 6 \mathrm{~nm})$ with an FCC structure. The UV-Vis absorption spectrum shows surface plasmon resonance at $420 \mathrm{~nm}$, which is a characteristic of silver nanoparticles. The measured antibacterial activity of the synthesized silver nanoparticles clearly demonstrates the excellent activity of these nanoparticles against several pathogenic bacteria, showing the highest activity for P. aeruginosa. The method used in the present paper is relatively simple, fast, and environmentally friendly, and this can be scaled up for the bulk production of highly monodispersed silver nanoparticles, as well as other noble metals. This opens the opportunity for numerous applications of these nanoparticles to produce effective antibacterial agents for the management of emerging multidrug-resistant pathogenic bacteria.

Author Contributions: Conceptualization, F.A. (Faheem Ahmed); Data curation, S.D. and N.M.S.; Formal analysis, F.A. (Faheem Ahmed), N.A. (Nishat Arshi), S.D., S.K. and N.A. (Naushad Ahmad); Funding acquisition, S.Y.A.; Methodology, F.A. (Faheem Ahmed), N.A. (Nishat Arshi), S.D., F.A. (Fadwa Albalawi) and N.A. (Naushad Ahmad); Project administration, S.Y.A.; Validation, S.D. and N.M.S.; Visualization, S.Y.A., S.D., F.A. (Fadwa Albalawi) and S.K.; Writing-original draft, F.A. (Faheem Ahmed) and S.D.; Writing-review \& editing, F.A. (Faheem Ahmed), S.Y.A., F.A. (Fadwa Albalawi), N.A. (Nishat Arshi), S.D., S.K., N.M.S. and N.A. (Naushad Ahmad). All authors have read and agreed to the published version of the manuscript.

Funding: This research was funded by Deanship of Scientific Research at King Saud University, grant number RGP-1441-543" and the APC was funded by Research Group number RGP-1441-543.

Data Availability Statement: Available on request.

Acknowledgments: Authors are grateful to the Deanship of Scientific Research at King Saud University for its funding of this research through Research Group number RGP-1441-543.

Conflicts of Interest: The authors declare no conflict of interest.

\section{References}

1. Kusaka, T.; Takagi, Y. The Mechanism of a Slime Formation by Microorganisms in a Paper Mill. J. Antibact. Antifungal Agents 1992, 20, 451.

2. Saito, M. Influence of Particle Size on the Antibacterial Activity of Zinc Oxide. J. Antibact. Antifungal Agents 1993, $21,17$.

3. Tsunoda, Y.; Egawa, H.; Yuge, O. Preparation and High Bacteriostatic Action of the Activated Carbons Possessing Ultrafine Silver Particles. J. Antibact. Antifungal Agents 1992, 20, 571.

4. Williams, D.N.; Ehrman, S.H.; Holoman, T.R.P. Evaluation of the Microbial Growth Response to Inorganic Nanoparticles. J. Nanobiotechnol. 2006, 4, 3. [CrossRef]

5. Gong, P.; Li, H.; He, X.; Wang, K.; Hu, J.; Tan, W.; Zhang, S.; Yang, X. Preparation and Antibacterial Activity of Fe $\mathrm{O}_{4} \mathrm{Ag}$ Nanoparticles. Nanotechnology 2007, 18, 285604. [CrossRef]

6. Banoee, M.; Seif, S.; Nazari, Z.E.; Fesharaki, P.J.; Shahverdi, H.R.; Moballegh, A.; Moghaddam, K.M.; Shahverdi, A.R. ZnO Nanoparticles Enhanced Antibacterial Activity of Ciprofloxacin against Staphylococcus Aureus and Escherichia Coli. J. Biomed. Mater. Res. B. Appl. Biomater. 2010, 93, 557. [CrossRef]

7. Gajjar, P.; Pettee, B.; Britt, D.W.; Huang, W.; Johnson, W.P.; Anderson, A.J. Antimicrobial Activities of Commercial Nanoparticles against an Environmental Soil Microbe, Pseudomonas Putida KT2440. J. Biol. Eng. 2009, 3, 9. [CrossRef] [PubMed]

8. Maliszewska, I.; Sadowski, Z.J. Synthesis and Antibacterial Activity of Silver Nanoparticles. Phys. Conf. Ser. 2009, 146, 012024. [CrossRef]

9. Jeyaraj, M.; Sathishkumar, G.; Sivanandhan, G. Biogenic Silver Nanoparticles for Cancer Treatment: An Experimental Report. Colloids Surf. B Biointerfaces 2013, 106, 86-92. [CrossRef] 
10. Vijayaraghavan, K.; Nalini, S.P.; Prakash, N.U.; Madhankumar, D. One Step Green Synthesis of Silver Nano/Microparticles Using Extracts of Trachyspermum Ammi and Papaver Somniferum. Colloids Surf. B Biointerfaces 2012, 94, 114-117. [CrossRef]

11. Magudapathy, P.; Gangopadhyay, P.; Panigrahi, B.K.; Nair, K.G.M.; Dhara, S. Electrical Transport Studies of Ag Nanoclusters Embedded in Glass Matrix. Phys. B 2001, 299, 142. [CrossRef]

12. Gu, H.; Ho, P.L.; Tong, E.; Wang, L.; Xu, B. Presenting Vancomycin on Nanoparticles to Enhance Antimicrobial Activities. NanoLetter 2003, 3, 1261. [CrossRef]

13. Iqbal, N.; Kadir, M.R.A.; Malek, N.A.N.N.; Mahmood, N.H.B.; Murali, M.R.; Kamarul, T. Characterization and Antibacterial Properties of Stable Silver Substituted Hydroxyapatite Nanoparticles Synthesized through Surfactant Assisted Microwave Process. Mater. Res. Bull. 2013, 48, 3172-3177. [CrossRef]

14. Pal, A.; Shah, S.; Devi, S. Synthesis of Au, Ag and Au-Ag Alloy Nanoparticles in Aqueous Polymer Solution. Colloids Surf. A Physicochem. Eng. Asp. 2007, 302, 51. [CrossRef]

15. Reetz, M.T.; Helbig, W. Size-Selective Synthesis of Nanostructured Transition Metal Clusters. J. Am. Chem. Soc. 1994, $116,7401$. [CrossRef]

16. Choi, S.H.; Zhang, Y.P.; Gopalan, A.; Lee, K.P.; Kang, H.D. Preparation of Catalytically Efficient Precious Metallic colloids by $\gamma$-Irradiation and Characterization. Colloids Surf. A Physicochem. Eng. Asp. 2005, 256, 165. [CrossRef]

17. Willwohl, H.; Wolfrum, J.; Zumbach, V.; Albers, P.; Seibold, K. Production and Characterization of Highly Dispersed Catalytic Active Platinum and Palladium Powders by Excimer Laser Photolysis. J. Phys. Chem. 1994, 98, 2242. [CrossRef]

18. Li, Z.; Li, Y.; Qian, X.F.; Yin, J.; Zhu, Z.K. A Simple Method for Selective Immobilization of Silver Nanoparticles. Appl. Surf. Sci. 2005, 250, 109. [CrossRef]

19. Suslick, K.S.; Choe, S.B.; Cichowlas, A.A. Sonochemical Synthesis of Amorphous Iron. Nature 1991, 353, 414. [CrossRef]

20. Hayakawa, K.; Iwama, S. Preparation of Ultrafine $\gamma$-Fe Particles by Microwave Plasma Processing. Cryst. Growth 1990, $99,188$. [CrossRef]

21. Ela, S.E.; Cogal, S.; Icli, S. Conventional and Microwave-Assisted Synthesis of ZnO Nanorods and Effects of PEG400 as a Surfactant on the Morphology. Inorg. Chim. Acta 2009, 362, 1855.

22. Fu-Ken, L.; Pei-Wen, H.; Yu-Cheng, C.; Chu-Jung, K.; Fu-Hsiang, K.; Tieh, C. Formation of Silver Nanorods by Microwave Heating in the Presence of Gold Seeds. Cryst. Growth 2005, 273, 439.

23. Perez, C.; Pauli, M.; Bazerque, P. Antibiotic Assay by Agar-Well Diffusion Method. Acta Biol. Med. Exper. 1990, 15, 113-115.

24. Aoki, K.; Chen, J.; Yang, N.; Nagasava, H. Charge-Transfer Reactions of Silver Stearate-Coated Nanoparticles in Suspensions. Langmuir 2003, 19, 9904. [CrossRef]

25. Nath, S.S.; Chakdar, D.; Gope, G. Synthesis of CdS and ZnS Quantum Dots and Their Applications in Electronics. Nanotrends $2007,2,3$.

26. Nath, S.S.; Chakdar, D.; Gope, G.; Avasthi, D.K. Effect of $100 \mathrm{MeV}$ Nickel Ions on Silica Coated ZnS Quantum Dots. Nanoelectron. Optoelectron. 2008, 3, 1. [CrossRef]

27. Guzman, M.G.; Dille, J.; Godet, S. Synthesis of Silver Nanoparticles by Chemical Reduction Method and Their Antibacterial Activity. World Eng. Technol. 2008, 43, 357-364.

28. Serra, A.; Filippo, E.; Re, M.; Palmisano, M.; Antisari, M.V.; Buccolieri, A.; Manno, D. Non-Functionalized Silver Nanoparticles for a Localized Surface Plasmon Resonance-Based Glucose Sensor. Nanotechnology 2009, 20, 165501-165508. [CrossRef]

29. Jose, R.M.; Jose, L.E.; Alejandra, C.; Katherine, H.; Juan, B.K.; Jose, T.R.; Miguel, J.Y. The Bactericidal Effect of Silver Nanoparticles. Nanotechnology 2005, 16, 2346.

30. Sawai, J.; Shouji, S.; Igarashi, H.; Hashimoto, A.; Kokugan, T.; Shimizu, M.; Kojima, H. Hydrogen Peroxide as an Antibacterial Factor in Zinc Oxide Powder Slurry. Ferment. Bioeng. 1998, 86, 521. [CrossRef]

31. Kim, J.S.; Kuk, E.; Yu, K.N.; Kim, J.H.; Park, S.J.; Lee, H.J.; Kim, S.H.; Park, Y.K.; Park, Y.H.; Hwang, C.Y. Antimicrobial Effects of Silver Nanoparticles. Nanomed. Nanotechnol. Biol. Med. 2007, 3, 95-101. [CrossRef] [PubMed]

32. Gangadoo, S.; Elbourne, A.; Medvedev, A.E.; Cozzolino, D.; Truong, Y.B.; Crawford, R.J.; Wang, P.Y.; Truong, V.K.; Chapman, J. Facile Route of Fabricating Long-Term Microbicidal Silver Nanoparticle Clusters against Shiga Toxin-Producing Escherichia Coli O157: H7 and Candida Auris. Coatings 2020, 10, 28. [CrossRef]

33. Goga, M.; Baláž, M.; Daneu, N.; Elečko, J.; Tkáčiková, L'; Marcinčinová, M.; Bačkor, M. Biological Activity of Selected Lichens and Lichen-Based Ag Nanoparticles Prepared by a Green Solid-State Mechanochemical Approach. Mater. Sci. Eng. C 2021, $119,111640$. [CrossRef] [PubMed]

34. Gangadoo, S.; Nguyen, H.; Rajapaksha, P.; Zreiqat, H.; Latham, K.; Cozzolino, D.; Chapman, J.; Truong, V.K. Inorganic Nanoparticles as Food Additives and their Influence on the Human Gut Microbiota. Environ. Sci. Nano 2021. [CrossRef] 